\title{
Resistir, destituir y habitar desde Latinoamérica: más allá del antagonismo y la subalternidad*
}

\author{
Resistance, destituent and habitation in Latin America: beyond \\ antagonism and subalternity
}

\author{
Resistir, destituir e habitar desde a América Latina: além do \\ antagonismo e da subalternidade
}

Mayra Nava**

\begin{abstract}
RESUMEN
La eficacia con que se ha expandido la forma de vida neoliberal

a nivel planetario puede explicarse por los diversos mecanismos biopolíticos-inmunitarios que se corresponden con sus valores y fundamentos, siendo principal dispositivo la democracia occidental. La inmunidad que se pone en marcha se sostiene principalmente en la lógica de seguridad a través de un despliegue de vigilancia y control policiaco y militar y, a su vez, en la lógica de inclusión-exclusión, que es quizá su mecanismo más sutil y que lo distingue de sus formas totalitarias, pues se basa en el control de las posibles resistencias y oposiciones al proyecto democrático inmunitario a través de uno de sus valores fundamentales: la integración e inclusión por medio de la neutralización y desactivación de la potencia transformadora de las resistencias. Este artículo problematiza las nociones dominantes de la resistencia en su dimensión teórica y política, sus límites y sus alcances ante este panorama biopolítico-inmunitario, para argumentar el modo en que las apuestas desde la vulnerabilidad, la lógica des-
\end{abstract}

Palabras clave: biopolíticainmunitaria, habitar, Latinoamérica, resistencia, vulnerabilidad.

\footnotetext{
* Este artículo se enmarca dentro de una investigación del Doctorado en Estudios Latinoamericanos de la Universidad Nacional Autónoma de México, UNAM, acerca de procesos de resistencia en América Latina ante el dominio biopolítico-inmunitario y su democracia, financiado por Consejo Nacional de Ciencia y Tecnología, CONACYT.

** Mexicana. Psicóloga social y maestra en Estudios Latinoamericanos por la UNAM. Candidata a doctora en el mismo posgrado. Ciudad de México, México. mayra.nava@ iztacala.unam.mx
} 
tituyente y el habitar en común desde Latinoamérica, se colocan como una vía efectiva con fuerza transformadora y combativa.

\begin{abstract}
The effectiveness with which the neoliberal way of life has expanded on a planetary level can be explained by the various biopolitical-immunitarian mechanisms that are consistent with its values and foundations, its main apparatus being Western democracy. The immunity that is put in place is mainly sustained by the logic of security through the deployment of police and military surveillance and control, and in turn by the logic of inclusion-exclusion. This, perhaps is its most subtle mechanism and distinguishes it from its totalitarian forms. It is based on the control of possible forms of resistance and opposition to the immunitarian democratic project through one of its fundamental values: integration and inclusion through the neutralization and deactivation of the transformative power of resistance. This article problematizes the dominant notions of resistance in their theoretical and political dimensions, their limits and their scope in the face of this biopolitical-immunitarian panorama. It argues that the way in which the challenges of vulnerability, the logic of dispossession and common habitation in Latin America are positioned as an effective path with transformative and combative force.
\end{abstract}

\section{RESUMO}

A eficácia com que o modo de vida neoliberal se expandiu em nível planetário pode ser explicada por vários mecanismos biopolítico-imunitários que correspondem a seus valores e fundamentos, sendo o principal dispositivo a democracia ocidental. A imunidade colocada em marcha é sustentada principalmente pela lógica da segurança através de uma mobilização de vigilância e controle policial e militar e, por sua vez, pela lógica da inclusão-exclusão, talvez seu mecanismo mais sutil e que a distingue de suas formas totalitárias pois se baseia no controle de possíveis resistências e oposições ao projeto democrático imunitário através de um de seus valores fundamentais: a integração e a inclusão por meio da neutralização e desativação do poder transformador das resistências. Este artigo problematiza as noções dominantes da resistência em sua dimensão teórica e política, seus limites e seu alcance neste panorama biopolítico-imunitário, para argumentar a forma como as apostas a partir da vulnerabilidade, da lógica destituidora e do habitar em comum da América Latina são colocadas como um caminho efetivo com força transformadora e combativa.
Keywords: biopoliticalimmunitarian, habitation, Latin America, resistance, vulnerability.

Palavras-chave: biopolíticaimunitária, habitar, América-latina, resistência, vulnerabilidade. 
La insurrección no respeta ninguno de los formalismos, ninguno de los procedimientos democráticos. Impone, como cualquier manifestación de gran magnitud, su propio uso del espacio público. Es, como cualquier huelga determinada, política de hechos consumados. Es el reino de la iniciativa, de la complicidad práctica, del gesto, la decisión prevalece en la calle, recordando a quien lo hubiera olvidado que "popular" viene del latín "populor", "asolar", "devastar". Es la plenitud de la expresión - en los cantos, en los muros, en las tomas de palabra- y, la nada de la deliberación. El milagro de la insurrección reside tal vez en esto: al mismo tiempo que disuelve la democracia como problema, figura inmediatamente un más allá de ella.

Comité INVISIBLE

\section{Biopolítica-inmunitaria, neoliberalismo y democracia}

El paradigma biopolítico-inmunitario en que se sostiene actualmente la democracia de mercado a nivel global emerge propiamente con la modernidad y se caracteriza por tomar la vida como objetivo del ejercicio de poder: gestionarla, administrarla, producirla, "hacer vivir, dejar morir" (Estévez, 2018; Foucault, 2000); en contraposición al antiguo régimen que tenía como propósito primordial ejercer el poder a través de la producción de la muerte. Al tomar la vida, el capitalismo-neoliberal y su democracia biopolítico-inmunitaria pretenden protegerla de todo aquello que suponga un riesgo para tal proyecto, protección desempeñada principalmente a través de la violencia legítima del Estado -pero no únicamente- (Benjamin, 2001). El sentido de tal mandato es suprimir la vida de su potencia e intensidad, volviéndola un asunto individualizado y privatizado, rompiendo de esta manera con la amenaza que supone para tal proyecto la vida en comunidad. Es necesario recordar que esa vida que toma como objeto de su protección no es cualquier vida, es la vida que a través de las diversas técnicas medicalizadoras y judicializadoras de gestión dan como producto la forma de vida neoliberal; el resto de formas de vida, entre más distantes a este proyecto más perseguidas serán, poniendo en marcha múltiples estrategias, como el fortalecimiento de la violencia estatal y sus aparatos, pero también a través de otros brazos del Estado, como el dispositivo médico que se ha encargado de controlar los cuerpos por medio de la imposición entre lo normal y anormal. En el caso más extremo, las vidas que más se opongan a ese despliegue de poder podrán ser aniquiladas por mecanismos necropolíticos. 
A lo largo de la historia del proyecto moderno y su sistema capitalista el paradigma biopolítico-inmunitario ha tenido dos expresiones principales que se han producido de acuerdo con las necesidades de tal sistema. La expresión más evidente han sido los gobiernos totalitarios de principios del siglo XX y las dictaduras militares en Latinoamérica de mediados del mismo siglo, donde los métodos violentos de persecución estatal a lo disidente no necesitaban ocultarse ni disfrazarse de mecanismos democráticos del Estado de Derecho. La otra expresión es la actual democracia occidental que se ha extendido como un proyecto globalizador de la mano del capitalismo. Este tipo de democracia, como sugiere Alain Brossat (2008) y Roberto Espósito (2009), es inmunitaria porque nace como un proyecto civilizatorio que pretende protegerse a toda costa de lo que pueda amenazarlo, desde lo que podría considerarse externo, pero particularmente del peligro interno. La inmunidad que se pone en marcha se sostiene, principalmente, en la lógica de seguridad a través de un despliegue de vigilancia y control policiaco y militar y, a su vez, en la lógica de inclusión-exclusión. Este es quizá su mecanismo más sutil y el que más lo distingue de sus formas totalitarias, pues se basa en el control de las posibles resistencias y oposiciones al proyecto democrático inmunitario, a través de uno de sus valores fundamentales: la integración e inclusión por medio de la neutralización y desactivación de la potencia transformadora de las resistencias. Es cierto que en el momento en que se perciba una oposición a este proyecto como una amenaza radical podrá aniquilársele incluso con las mismas estrategias heredadas de los regímenes totalitarios, sin embargo, la forma más común es tratar de neutralizarlas y pacificarlas, pues esto permite el sostenimiento de la lógica inmunitaria, tal como actúan las vacunas en los organismos vivos, el pharmakon, cura y veneno a la vez, manejo y administración de las posibles amenazas sin que se pretenda exterminarlas como fin último.

La democracia inmunitaria es un proyecto global con particularidades geopolíticas. En casi cualquier rincón del planeta al que miremos podremos dar cuenta de dicho proyecto, puesto que su locus es el mercado y no los Estados-nación, estos solo se han convertido en un garante de su desarrollo. De esta manera, las resistencias sociales que emergen no pueden ser únicamente opositoras al Estado, sino al proyecto inmunitario que encapsula al Estado moderno y al actual ca- 
pitalismo neoliberal. Remarcarlo es importante aunque parezca una obviedad, debido a que en la actualidad es posible distinguir movimientos, colectividades y diversas organizaciones políticas que se asumen como opositoras y resistentes a los modos violentos del Estado, pero que sin embargo no cuestionan de ninguna manera el orden capitalista, y los rasgos heteropatriarcales que constituyen a ambos, reduciendo sus reivindicaciones al cumplimiento del Estado de Derecho, es decir, al mantenimiento de la democracia inmunitaria y de la correcta administración de la violencia. Incluso apelando a las libertades de mercado: derecho de propiedad, individualidad, identidad, consumo. Este anhelo de privilegios particulares traducidos en derechos individuales se ha filtrado incluso en movimientos con tradición abiertamente opositora: movimientos campesinos, obreros, estudiantiles e incluso indígenas. A la democracia inmunitaria le es favorable la configuración de este tipo de reivindicaciones políticas que se expresan en la fragmentación de los movimientos sociales y en la conformación de esferas separadas o poco interconectadas en sus apuestas políticosociales.

El discurso de separación entre radicales y moderados, entre pacíficos y violentos o legítimos e infiltrados que se despliega desde los propios Estados, medios de comunicación y espacios académicos es parte de esa dinámica inmunitaria que solo contribuye a la intensificación y mantenimiento del conflicto al interior de la población civil, anulando con ello el reconocimiento de las afectaciones y apuestas en común ante el proyecto biopolítico-inmunitario. Actualmente, el medio más eficaz del desmantelamiento de la fuerza de una insurrección es calificarla de antidemocrática y violenta o atribuirle el anhelo único de la democracia, tal como ocurrió en al proceso de la llamada primavera árabe (2010-2013), cuando lo que se estaba poniendo en marcha sobrepasaba el imaginario de la democracia, no era simplemente el derrocamiento de un tirano que fácilmente podía ser sustituido por otro -seguramente autorizado por el gobierno estadounidense-; como lo señala uno de los testimonios de ese momento: "En Egipto, no hemos hecho la revolución en las calles con el simple objetivo de tener un Parlamento. Nuestra lucha, que pensamos compartir con ustedes, es bastante más amplia que la obtención de una democracia parlamentaria bien engrasada" (Comité Invisible, 2015, p. 56). Las estrategias neutralizadoras operan no solo respecto de las resistencias, insurrec- 
ciones y movimientos sociales, sino también al interior de los propios estados, cuando sus gobiernos pretenden impulsar algún mecanismo calificado de progresista y que pueda incomodar la economía liberal, inmediatamente. Como señala Dávalos (2010), los operadores del mercado trasnacional acusan esas políticas de antidemocráticas y/o populistas y, como hemos visto en Latinoamérica, cualquier gobierno con tendencias izquierdistas - aunque sean las más moderadas- es enseguida culpado de entorpecer el camino del desarrollo democrático. De esta manera, la democracia se ha convertido en el escudo de la economía neoliberal (Nava, 2019).

Ante este panorama es preciso replantearse la categoría de resistencia social en su sentido conceptual - y con ello también político-, pues como referimos anteriormente, la resistencia social en su dimensión más básica puede estar reforzando el proyecto de la democracia biopolítica-inmunitaria al sumarse a los valores del mismo, donde la oposición no tendría que ser necesariamente perseguida o erradicada, siempre y cuando esté integrada a través de su atenuación y, por ello, no constituya una amenaza. Coincidimos con Deleuze (en Bordeleau, 2019), cuando afirma que "cuando el poder deviene biopoder, la resistencia deviene poder de la vida" (p. 62), es decir, si el objetivo principal de la biopolítica-inmunitaria - y aquí es preciso señalar que tomamos particularmente la visión de Roberto Espósito (2009) — es la gestión y producción de la vida, las resistencias tendrían que estar forzosamente vinculadas a una forma de vivir que efectivamente se distancie y deserte de la forma de vida dominante, tanto en sus prácticas como en sus modos de subjetivación, aún más, cuando la expansión del poder biopolítico-inmunitario y su forma democrática ocurre de manera logística y por lo tanto técnica, se administra organizando la vida: calendarizando, suministrando, planificando, diseñando:

El poder es ahora inmanente a la vida tal y cómo esta es organizada tecnológica y mercantilmente (...) Quien determina el agenciamiento del espacio, quien gobierna los medios y los ambientes, quien administra las cosas, quien gestiona los accesos gobierna a los hombres. El poder contemporáneo se ha hecho heredero, por un lado, de la vieja ciencia de la policía, que consiste en velar "por el bienestar y la seguridad de los ciudadanos", y por el otro, de la ciencia logística de los militares. (Comité Invisible, 2015, pp. 90-91). 
En este sentido, la puesta en marcha de otras formas de vida está estrechamente relacionada con habitar el mundo de manera particular: como modo concreto de desmantelar esa logística y su infraestructura.

La resistencia como categoría analítica ha permitido comprender todo aquello que se ubique dentro del abanico de los movimientos sociales: insurrecciones, revueltas, luchas sociales, deserciones; cada una de ellas con apuestas y efectos distintos pero atravesadas por la noción de resistir. Sin embargo, hoy más que en otros tiempos es apremiante preguntarnos ¿cómo y a qué se le resiste? Incluso cuestionarnos si esa noción aún es pertinente, por lo menos tal y como la hemos entendido hasta ahora. En este escrito reflexionaremos respecto de esta categoría. En un primer momento haremos un acercamiento a sus contenidos y derivas principales para comprender sus alcances ante este panorama biopolítico-inmunitario, y después argumentaremos el modo en que las apuestas de habitar en común desde Latinoamérica se colocan como una vía efectiva con fuerza transformadora y combativa.

\section{La categoría resistencia: sus usos y sus límites políticos y teóricos}

Cuando se trata de investigaciones que tienen que ver con algún tipo de movimiento social o con algún sector marginalizado (ya sea religioso, de género, de etnias, etc.) la elaboración conceptual y teórica respecto de esta categoría de resistencia es regularmente limitada. Sucede que la mayoría de las veces se da por supuesto lo que se está entiendo por resistencia, su significado, su contenido teórico; en todo caso, lo más común ha sido designar las prácticas políticas de cualquier movimiento o colectivo social vulnerado como resistentes solo porque se encuentran en una posición subalterna, dejando de lado que una práctica resistente solo puede serlo en relación a las fuerzas de poder que identifica y a las que se opone, incluso, estas prácticas adquieren alcances y efectos distintos dependiendo de la lectura de la conflictividad en la que participan. Esta situación —estando de acuerdo con Modonesi (2006)—, nos plantea un problema teórico y conceptual: ¿qué es la resistencia? Este mismo autor corrobora la idea de que existen pocos estudios académicos que trabajen a fondo el concepto de resistencia, por mucho que se utilice el término, lo que no quiere decir que se trabaje conceptualmente. Asimismo, Modonesi menciona que siempre que se quiera aproximar a las formas 
de resistencia social no solo es importante acercarse a lo que se ha dicho teóricamente, sino a las elaboraciones políticas que hacen los mismos colectivos o movimientos sociales. Agrega que son dos las acepciones que circulan principalmente respecto de la resistencia social: la teórica y la política. La primera de carácter débil y la segunda de carácter fuerte: "En el plano teórico, las definiciones más elaboradas de la categoría de resistencia configuran una versión débil, que podríamos llamar subalterna. En el plano político, las implicaciones en el uso de la categoría conforman una versión fuerte, que podríamos llamar antagonista" (Modonesi, 2006, p. 2). Es decir, para este autor la idea de una elaboración de resistencia débil consiste en que teóricamente se le coloca al lado de la dominación y como la otra cara de la moneda del poder, la resistencia siempre como subordinada a algo, por ello la considera como débil, más no incorrecta:

La piedra de tope que sostiene el edificio teórico es la ubicación (correcta) de la resistencia en el marco de las relaciones de dominación y de poder. A partir de allí, se abre la posibilidad de reconocer la negociación permanente que caracteriza estas relaciones, en la cual existen márgenes de maniobra tanto para los dominados como para los dominantes. Los márgenes de acción de los dominados, el terreno de la resistencia, se vuelven así el objeto de análisis refinados que revelan los aspectos creativos de la acción colectiva. (Modonesi, 2006, p. 3).

A su vez, Modonesi resalta un punto interesante que pocas veces es tratado conceptualmente: la idea de que subalternidad y antagonismo son asuntos distintos. La primera supone un rango de inferioridad que se opone a un dominio, la segunda en cambio, refiere a una posición distinta, el reconocimiento de un enemigo, de un oponente. Si tomamos en cuenta este aspecto, la forma en que se lee y se enuncia la resistencia tiene derivas totalmente diferentes. Ser resistente desde la subordinación tomará ciertas formas, tal vez referentes a la contención de un poder y desde el antagonismo otras, incluso más desafiantes que requieren la lectura del otro como Otro, como un conflicto abierto, declarado entre una forma de vivir y otra. Aunque ello no quiere decir que no se puedan ocupar ambas posiciones:

Esta perspectiva se dirige hacia la construcción de una noción de antagonismo que rebase su acepción común como sinónimo de 
contraposición de clase y se sitúe en el terreno de los procesos de construcción subjetiva de los movimientos sociales. En este sentido, el antagonismo puede configurarse como la contraparte de la categoría de subalternidad, formando una diada. Dos categorías complementarias que permiten visualizar dos caras de todo proceso de construcción subjetiva en un contexto de conflicto social e indicar una tensión fundamental en la formación de los movimientos sociales. (Modonesi, 2006, p. 8).

La resistencia ha sido conceptualizada de manera dominante a partir de estas dos lecturas basadas en posiciones identificables: el antagonismo y la subalternidad; la primera ligada de manera directa a la lectura marxista del poder, el Estado burgués y la lucha de clases; y la segunda, ligada a la visión de los actuales estudios poscoloniales. Ambos planteamientos insertados en la matriz clásica del pensamiento político moderno en la línea filosófica hegeliana, entendiendo el poder y la resistencia como lugares determinados, posiciones cuya tensión y conflictividad solo podrá ser resuelta a través de la vía dialéctica. Hay detrás de dichos enfoques una noción de poder solo en el sentido represivo, unilateral, negativo y jerárquico que coloca énfasis en la figura del Estado, pero oscurece todas las otras formas de poder, particularmente en ciertas lecturas marxistas. Coincidimos con Han (2016) cuando refiere que esta visión no permite una lectura compleja de las relaciones de poder y resistencia, pues las concibe como una relación binaria y causal, cuando no todo poder trae consigo una condición de resistencia ni todas las relaciones sociales están atravesadas por una sola dialéctica, puesto que no todo poder es represivo o jerárquico. En este sentido, es bien sabido - desde Foucault-que el poder puede ser productivo. Para Byung-Chul-Han (2016), "hay que tener en cuenta la múltiple dialéctica del poder. El modelo del poder jerárquico, según el cual el poder se irradia simplemente desde arriba hacia abajo no es dialéctico" (p. 17).

Asumir y comprender la resistencia desde una posición subalterna tendrá efectos que podrán llevar a una exigencia del reconocimiento de este lugar por parte del poder, casi siempre a través de la identificación de un papel de víctima por parte del subalterno. Por su parte, la visión de resistencia desde el lugar de antagonismo ha derivado en la concepción de un sujeto revolucionario asignado a la figura del obrero, que a través 
de la dialéctica de la lucha de clases llevará a la anhelada dictadura del proletariado; desde ese posicionamiento hay una declaración abierta de la lucha por el poder, la resistencia tendrá que resultar, entonces, en la toma del poder por parte de los antagonistas. La idea de subalternidad apunta efectivamente a hacer visibles diversas formas de poder no solo estatales (Banerjee, 2014), sin embargo, queda fácilmente atrapada en un lugar inamovible que es regularmente un tipo de identidad que al consolidarse puede reafirmar también la posición de quienes ostentan un poder, produciendo una paradoja de la cual sería difícil salir y donde las apuestas de emancipación se vuelven turbias.

Ambos planteamientos arrojan coordenadas para comprender la resistencia en un sentido práctico y político, sin embargo, ante el tipo de poder biopolítico-inmunitario que experimentamos actualmente pueden parecer limitados y poco efectivos, sobre todo porque giran hacia la reivindicación de una política identitaria, es decir, en un lugar reconocible que por lo tanto puede ser fácilmente atacado de manera directa o neutralizado por vía de la inclusión. No es casual que alrededor de todo el planeta se estén intensificando los brotes de movimientos que se desprenden de una lógica de identidad referida a una posición social específica como el género, la clase o la etnia -como los llamados Chalecos amarillos en París y Bélgica; los indignados de Madrid; los Occupy en Wall Street; y el primer momento de los piqueteros en Buenos Aires-donde lo que se pone en el centro de la insurrección es una inconformidad común, el modo en que diversas existencias se asumen trastocadas en múltiples aspectos por el capitalismo neoliberal, más allá de identidades particulares, pues estas quedan borradas. Esto no supone de ninguna manera que no haya quienes efectivamente resulten más afectados que otros, sin embargo, lo que importa en este tipo de expresiones insurreccionales es distinguir cómo resultamos afectados por el proyecto capitalista en su versión biopolítica-inmunitaria y no la conformación de diferenciaciones identitarias. Bordelau (2019) sugiere, en este sentido, el modo en que en los tiempos actuales la idea de fortalecer las diferencias identitarias como modo de resistencia amenaza las posibilidades de una resistencia en común:

La identidad minoritaria se ha convertido en un componente clave del "nuevo espíritu del capitalismo" (...) Como explica François Cusset "la diferencia sobre todo terminó por autorizar una segmen- 
tación más fina del mercado, una extensión del capital a las esferas de la afinidad furtiva y de la intimidad clandestina, de la pequeña o de la invisible diferencia. Aun cuando debía invertir las fuerzas uniformizantes del capitalismo occidental , la diferencia... se transformó, mientras tanto, en la principal herramienta de gestión del poder. (p. 20).

Esto no significa que la homogeneización de la vida no siga siendo un objetivo del orden actual, sino que esta se efectúa a través de la segmentación y producción de diferencias, o más bien, de diversidades superficiales arraigadas en una subjetividad identitaria, es decir, individualista. Este tipo de diversidad alentada desde la democracia inmunitaria no es considerado una amenaza, pues opera dentro de los mismos términos de sentido del poder biopolítico neoliberal. Suely Rolnik (2019) señala que en la actualidad, la intensificación de las fuerzas conservadoras alrededor del planeta puede entenderse porque estas y el proyecto neoliberal comparten la misma moral y el mismo modelo de identificación subjetiva que denomina como inconsciente colonial-capitalístico. Este tipo de proceso colonial - nos dice Paul Preciado (2018) siguiendo a Rolnik (2019)—, se caracteriza por la aprehensión de la fuerza vital, lo cual significa la reducción de la experiencia de vida a la figura de sujeto (autónomo, libre, racional, moderno), anulando la complejidad de las afectaciones del mundo sobre los cuerpos, restringiéndolos a la búsqueda de una identidad referida a un derecho o privilegio que la proteja, tal como opera la lógica biopolítica inmunitaria. De esta manera, un movimiento social que se sostenga en la reivindicación identitaria - de corte liberalserá fácilmente administrable y transformable en mercancía, a través de la producción de una subjetividad liberal humanista a la que ya Foucault (citado en Bourdelau, 2019) había criticado y asocia con la lógica humanista dominante:

El humanismo es lo que ha inventado paso a paso estas soberanías sometidas que son: el alma (soberana sobre el cuerpo, sometida a Dios), la conciencia (soberana en el orden del juicio, sometida al orden de la verdad), el individuo (soberano titular de sus derechos, sometido a las leyes de la naturaleza o las reglas de la sociedad), la libertad fundamental (interiormente soberana, exteriormente consentidora y "adaptada a su destino"). (p. 36). 
Hasta aquí podemos dar cuenta de dos grandes problemáticas en la concepción dominante de la resistencia que están vinculadas: por un lado, la idea clásica de una oposición dialéctica que encuentra su razón de ser precisamente en eso a lo que se opone; y por otro, el lugar de subalterno con sus diversas derivas identitarias. Ambas concepciones conciben la resistencia como un lugar determinado desde el cual se resiste, noción que ante las condiciones actuales tiene que ser replanteada. Para Franco Berardi (2013), por ejemplo, la idea de la dialéctica como superación solo puede ser pensada en relación con el concepto histórico de totalidad y totalización, noción que no tiene cabida en el proceso de globalización y financiarización actual:

El concepto de totalidad implica un proceso en el cual aquello que es parte se disuelve y se conserva al mismo tiempo, se niega para reconocerse como un simple momento de una síntesis más alta donde la parte es negada y conservada simultáneamente. Se trata de un concepto esencialmente histórico. La totalización es el proceso mediante el cual aquello que se da en su separación es disuelto y subsumido, es decir, traducido en su negación, gracias a la cual este encuentra su alma, su vocación y su verdad. (pp. 58-59).

La globalización, en cambio "significa integración funcional de partes que mantienen su parcialidad independiente y, no obstante, funcionan conjuntamente gracias a interfaces que no modifican la interioridad pero la conectan recambiando el conjunto" (Berardi, 2013, p. 59). No hay negación de ninguna de las partes, todas son integradas funcionalmente y, por lo tanto, no hay nada que superar. Este pensamiento dialéctico se ha convertido en un dominio ontológico y metafísico en la filosofía política y en los movimientos sociales y revolucionarios incluso en Latinoamérica, pensamiento que se ha expresado, como señala Berardi (2013), en una perspectiva finalista, la cual supone que "a la totalidad existente del capitalismo debe seguir una totalidad superior. La totalidad fragmentada de la alienación, la totalidad de las contradicciones tiende a una superación, hacia una totalidad invertida que recomponga aquello que ahora se presenta separado" (p. 74). Los regímenes de corte socialista ya nos han demostrado que no hay tal superación, sino actualización e intensificación del capitalismo. 
Para Carla Lonzi (2004), el principio dialéctico para entender el poder y la resistencia es limitado y oscurecedor de múltiples formas de poder y dominio que se han perpetuado, incluso al interior de movimientos revolucionarios y que también han impedido dar cuenta de formas de resistencia que desde ese lente teórico y político no pueden reconocerse. Sostiene, además, que esa lectura del poder es sumamente masculina, pues "la relación hegeliana amo-esclavo es una relación interna del mundo masculino, y es ella a la que se refiere la dialéctica, en términos deducidos exactamente de las premisas de la toma de poder" (Lonzi, 2004, p. 28). En ese sentido, Lonzi (2004) invita a reflexionar respecto de las aspiraciones de los sectores oprimidos a ocupar el poder o ser reconocidos e insertados por este y afirma que esas pretensiones son una actualización del yugo colonizador, el que se traduce en deseos de igualdad con quienes ostentan algún tipo de privilegio: "La igualdad es todo lo que se les ofrece a los colonizados en el terreno de las leyes y los derechos. Es lo que se les impone en el terreno cultural. Es el principio sobre cuya base el colono continúa condicionando al colonizado" (p. 28).

Acerca de esto, Gutiérrez (2017) indica que actualmente existe cierta confusión respecto de las exigencias de diversas luchas sociales: se crea la sensación, hacia el interior de las mismas y como proyección social, de que la principal aspiración de los movimientos sociales es cultural y por lo tanto de reconocimiento, cuando la disputa fundamental es de corte material y en el caso particular de los movimientos por la defensa del territorio se trata de una disputa por la riqueza material. Nosotros agregamos al respecto, que por ser una disputa material es una lucha por la vida, específicamente por la forma de vida y el modo en que hacemos habitable un mundo como este. Coincidimos también con Gutiérrez (2017) cuando afirma que pocos son los movimientos que no se han dejado seducir por las "políticas pluriculturales y multiculturales absolutamente ligadas a la idea neoliberal de articular a todos y de administrar diferencias en términos de derechos concedidos". Si bien como señala Lonzi (2004), deberíamos cuestionarnos si lo que se anhela desde las luchas sociales es ser igualados por medio del reconocimiento o disputarnos el acceso al privilegio y a la toma de poder, también consideramos que no debemos renunciar al poder, en su sentido de acción sobre el mundo, de posibilidad de crear y transformar no como sujetos de cambio y revolución, sino 
como existencias en común a una forma-de-vida no neoliberal. Someterse a la idea de sujeto es renunciar a la posibilidad de un poder, para Bourdelau (2019), siguiendo a Foucault es necesario desprendernos y desbordar los límites que determinan al sujeto de derecho humanista de las democracias liberales para abrir paso a "la multiplicidad de los devenires-revolucionarios, la ventana de politización más allá del liberalismo" (p. 37).

Sin embargo, seguimos fortaleciendo el pensamiento moderno predominante que se ha configurado sobre la base de la noción de identidad y de la anulación de la diferencia, entendida como señala Berardi (2013), como aquello que acontece de forma contraria a la identidad, pues la diferencia es devenir. Esto trae consigo implicaciones importantes, particularmente cuando hablamos desde el pensamiento latinoamericanista en su dimensión política e intelectual y de propuestas que se realizan desde el Sur epistemológico, pues aún no hemos podido salir del paradigma moderno del Sujeto, la Historia, la Verdad - a la que muchas propuestas revolucionarias se suman-. En ciertas perspectivas de los estudios culturales, por ejemplo, la apuesta emancipatoria es colocada nuevamente en la identidad, ya sea sexual o étnica y "al querer exponer demasiado la afirmación de un derecho a la diferencia performativa nos hace perder de vista los problemas del apego a la identidad y del gobierno por individualización, tal como diagnosticó Foucault" (Bordeleau, 2019, p. 25). Al respecto, Berardi (2013) sostiene que:

Lo moderno pone en funcionamiento una máquina de reducción de la diversidad de las existencias humanas, o sea una máquina de homologación que la filosofía idealista supone perfecta, mientras que en la realidad de la historia moderna se vuelve interminable y totalitaria. La totalidad nunca se realiza como superación de las particularidades, sino que se limita a oprimir las particularidades, sobreponiéndoles una máquina policial. (p. 79).

Hasta aquí es evidente la idea de poder que prepondera desde la clásica lectura dialéctica, el poder entendido desde un modelo arborescente y por tanto jerárquico, que coloca en alguna figura y lugar determinado al poder: Estado, mercado, clase social, Iglesia. Como si fuera efectivamente posible encontrarlo arraigado en un solo lugar. Para Lopetegi de la Granja (2009), dicha lectura resulta obsoleta. 
Si en cambio, como señala el mismo Lopetegi de la Granja (2009) siguiendo a Foucault, entendemos el poder como una trama de relaciones y no como algo que puede poseerse o atribuirse únicamente a una figura en particular; nuestra lectura será más amplia y compleja, pues las resistencias tampoco corresponderán a un lugar asignado. Por supuesto, esto "no implica que no podamos hablar de núcleos en los que el poder se condensa más o menos (centros de poder), o de estancamiento y persistencia de ciertos juegos de poder a lo largo del tiempo (estados de dominación)" (Lopetegi de la Granja, 2009, p. 195); pero no será el objetivo principal, y en ese sentido, la resistencia no podrá ser únicamente entendida como oposición reproductora del poder al que se opone. Lopetegui de la Granja (2009) pone como ejemplo de ese juego de poder en el que comúnmente quedamos atrapados al llamado conflicto vasco y señala cómo este se ha convertido en dispositivo reproductor del orden al alimentar una conflictividad que termina constituyendo y fortaleciendo al poder al que se enfrenta, porque a la vez se configura su propio lugar de resistente-opositor:

El conflicto vasco es sobre todo el espectáculo de un conflicto que se concreta en tanto que realidad espectacular. Espectacular por separado de la vida cotidiana, como lucha privada ETA-Estado; y espectacular porque la oposición separada de perspectivas políticas divergentes no hace sino ocultar la "unidad de miseria" subyacente para asegurar su persistencia. Las diferentes posiciones contrapuestas no hacen sino confirmar de forma ininterrumpida una realidad idéntica (obvia/tautológica) sin posibilidad de apertura coyuntural alguna. Todas las luchas en el interior del juego político sobredeterminante contribuyen a la reproducción de una misma realidad que deviene simple reiteración ininterrumpida de lo mismo. (p. 196).

Estos juegos de poder y la lectura de la conflictividad sociopolítica en términos binarios sostienen la lógica biopolítico-inmunitaria del proyecto capitalista-neoliberal de la que hemos hablado. Coincidimos con Marina Garcés (2002) cuando advierte que una de las derivadas de este tipo de lectura de la realidad es quedar atrapados en la idea de lo posible o de los mundos posibles que tanto es reivindicado desde los movimientos sociales y el pensamiento emancipatorio tradicional, idea que aunque parece alentadora en realidad captura los procesos 
de resistencia al reducirlos evidentemente a lo que puede ser efectuado y no otra cosa, aquello que no ha sido pensado o imaginado. En otro momento de la historia, quizá hace 40 años y teniendo como referencia los años 60 del siglo pasado y su efervescencia social, la idea de otros mundos posibles podía hacer sentido, sin embargo, ubicados en las circunstancias actuales -donde lo posible se conformó como realidad capitalista - apostar a los posibles es aventurarse con la pasividad de la espera; es otra vez colocarse en una perspectiva finalista de una utopía por venir y no de un ahora que nos exige hacer, actuar, implicarnos. La subversión, nos dice Marina Garcés (2002), solo puede devenir fuera de la noción de lo posible, puesto que esta problemática "se mide, paradójicamente, por las realidades que dibuja. Y el verdadero problema que nos plantea hoy es el de explicar cómo en toda opción, alternativa o elección, se confirma la obviedad de un mismo mundo" (p. 1). Lo que aquí se plantea no significa de ninguna manera una resignación respecto del mundo que vivimos o una renuncia al combate del mismo, por el contrario, significa posicionarse en la subversión permanente, pero no desde la clásica idea del antagonismo que reduce la resistencia a su versión reactiva y negativa de oponer, contener, permanecer desde el lugar y la identidad del oprimido o del subalterno y donde solo se puede aspirar a los modos democráticos. Muchas de las insurrecciones y movimientos actuales exigen mirar por fuera de lo posible, como queda referido en un testimonio del documental Get Rid of Yourself de Bernadette Corporation acerca de las protestas contra el G-8 en Génova:

Ellos dicen "Otro mundo es posible". Pero no queremos otro mundo, otro orden, otra justicia: otra pesadilla lógica. No queremos una gobernanza global, ser pulcro, ser ecológico, estar certificado por Porto Alegre. Queremos este mundo. Queremos este mundo como caos. Queremos el caos de nuestras vidas, el caos de nuestras percepciones, el caos de nuestros deseos y nuestras repulsiones. (citado en Bourdelau, 2019, p. 49).

"No hay otro mundo, hay simplemente otra forma de vivirlo", nos dice el Comité Invisible (2015) citando a Jacques Mesrine y con ello nos invitan a asumir las implicaciones del ahora, del momento en el que vivimos. Sostienen que las luchas sociales (particularmente del siglo pasado) nutrieron su resistencia apostándole a un porvenir. Hoy la 
situación es diferente y urge habitar el mundo de otra manera, porque habitar siempre tiene que ver con el presente y a diferencia de otros momentos de la historia de eso que hemos denominado humanidad, el futuro está más en duda que nunca; como sostiene Colectivo Situaciones (2002): "Las movilizaciones actuales han abandonado las certezas respecto de un futuro provisorio. La presencia de la multitud en las calles no prolonga el espíritu de los años 70" (p. 78). El mundo que conocemos está llegando al límite no solo simbólico del ya habían hablado algunos autores, sino a su límite material, por más que nos imaginemos otros mundos, lo más seguro es que este tenga sus días contados y con ello toda la vida, no solo la humana; por ello, no hay lugar para la espera:

La esperanza, ese muy ligero pero constante impulso hacia el mañana que se nos comunica día tras día, es la mejor agente del mantenimiento del orden. Se nos informa cotidianamente de problemas contra los que no podemos hacer nada, pero para los que sin duda mañana habrá solución. (Comité Invisible, 2017, pp.16-17).

En este sentido, quienes mejor han entendido la situación y la necesidad de actuar en el ahora son los pueblos ancestrales. Siempre lo han entendido, pero es en estos momentos en que sus llamados producen más eco: son ellos quienes han sabido que no hay implicación más real con el mundo que habitarlo y que habitar supone configurar y hacerse de un territorio cuya vinculación es el vivir mismo, un vivir más allá de lo humano, sus inventos y su infraestructura. Para los pueblos ancestrales latinoamericanos el territorio no es un agregado o un escenario en el que ocurre la vida del hombre, es la condición de posibilidad de la vida y el vivir mismo, es una cualidad del mundo común. Sin embargo, para quienes hemos vivido la ilusión de ser occidentales el llamado a comprometerse con el entorno resulta novedoso, porque sentimos cada vez con mayor cercanía el agotamiento del mundo. Respecto de esto, Bruno Latour (2019) señala que es justo en la actualidad que la sensación de perder el mundo es colectiva, por el enfrentamiento a la realidad del cambio climático como un fenómeno que no es natural o evolutivo, sino producto del capitalismo mundial. Es como si Occidente hubiera descubierto que hay un mundo y que es finito; Latour señala que para los occidentales la tierra en la que hemos vivido era una tierra utópica que se extendería infinitamente a través 
de la modernización, utopía que nunca tuvo fundamentos materiales. Ante esta situación, nos dice este autor, resulta urgente un aterrizaje, bajar a la tierra, volver a lo terrestre:

Si aterrizásemos en lo terrestre, podríamos empezar a definir un mundo común. Entonces ya no podríamos permitirnos decir que no hay transformación climática, que los problemas de salud no nos conciernen, que la reproducción de abejas no es nuestro problema. (Latour, 2019, párrafo 29).

Así, lo que para algunos significa una apuesta actual y necesaria de resistencia, para otros ha significado una forma de vivir anterior a la modernidad y sus despojos, pero que hoy adquiere rasgos de resistencia.

\section{Resistir: una apuesta desde la vulnerabilidad del cuerpo}

De acuerdo con lo que hasta aquí hemos problematizado, la resistencia social como categoría de análisis, comprensión y acción política se complejiza. Consideramos que habría que ir más allá de su simple uso como adjetivo calificativo de cualquier práctica que corresponda a quienes se posicionen en el lugar de la subalternidad, la oposición o el antagonismo. La resistencia no es una cualidad que le pertenezca a una identidad o posición marginal o liminal:

Definida de esta forma, la resistencia sugiere la idea de un ser-encontra de toda forma de poder. De hecho, para aquel que formula el poder de tal modo, como exterior a sí mismo, diferente de sí mismo, resistir es estar del lado correcto. Uno de los mayores aportes del pensamiento foucaultiano de la resistencia consiste en desdibujar aquella división un poco facilista y moralista entre poder y resistencia. De ahí la idea de una microfísica del poder que piensa la resistencia como el resultado de un libre juego de fuerzas, y no simplemente como reacción, siempre secundaria de un grupo o de un individuo que ha sido perjudicado. Posibilidad entonces de una resistencia que no sea simplemente "reaccionaria", es decir, ontológicamente secundaria respecto del poder que la habría estimulado. Pues pensada en términos reactivos, la resistencia tiene necesariamente un corto aliento. (Bourdelau, 2019, p. 54). 
Su raíz etimológica del latino -sistere, que se refiere a mantenerse, detener, oponer y su intensificación en el prefijo re han encerrado la potencia de la comprensión de esta categoría, que además ha sido envuelta en una concepción de corte masculinista y paternalista al suponer que quienes resisten tendrían que salir, enfrentar y deshacerse de un estado de vulnerabilidad que impide la puesta en marcha de la resistencia o asumiendo que la resistencia es un estado de inferioridad política, de pura precariedad que necesita y exige la protección y reconocimiento de los poderes que los colocan en esa posición. Lectura que para nosotros está afincada en las dos perspectivas dominantes de la resistencia y el poder que hasta aquí hemos referido: el antagonismo y la subalternidad. A diferencia de esto, la resistencia para nosotros, solo puede emerger de una condición de vulnerabilidad, no de su reconocimiento racional, sino de un reconocimiento que solo puede pasar por lo sensible y por lo tanto por la corporalidad, o para ser más precisos, por la intercorporalidad:

si aceptamos que parte de lo que es un cuerpo (y esto es por el momento una declaración ontológica) es su dependencia de otros cuerpos y redes de apoyo, entonces estamos sugiriendo que no es del todo correcto concebir los cuerpos individuales como algo completamente distinto unos de otros. Por supuesto, tampoco es que estén fusionados en una especie de cuerpo social amorfo, pero si no podemos conceptualizar fácilmente el significado político del cuerpo humano sin entender esas relaciones en las que vive y se desarrolla, no conseguimos el mejor escenario posible para los diversos fines políticos que buscamos alcanzar. (Butler, 2014, p. 3).

La vulnerabilidad es algo que nos es común. En este sentido, la resistencia poco tiene que ver con un supuesto estado de conciencia o ideología política, y por consecuencia con el sujeto moderno racional y autónomo. Pensadoras como Judith Butler (2014), Suely Rolnik (2019), María Inés García Canal (2005), Raquel Gutiérrez (2017) y Marina Garcés (2002) han reflexionado respecto de la resistencia desde un lugar que cuestiona y se aleja de la filosofía política dominante tanto en Europa, como en Estados Unidos y América Latina. Con sus necesarias diferencias todas ellas coinciden en la importancia de la condición de vulnerabilidad para la puesta en marcha de las prácticas resistentes, pues solo quien se reconoce afectado puede resistir. La resistencia 
como una afectación, como un acto que irrumpe, ya sea relaciones, el orden de las cosas, la cotidianidad, entornos, dominios. Resistencia y poder como un juego de afectaciones mutuas: "Afectar es ejercer el poder, afectarse es la capacidad de resistencia, la cual aparece en todos los actos de ejercicio del poder. Así, pues, ejercicio del poder y resistencia son indisolubles" (García Canal, 2005, p. 118).

La vulnerabilidad es la posibilidad de dejarse afectar, posibilidad que está más allá de la noción de lo humano, sino que se extiende a todo aquello que está vivo. Es más, no hay manera en que la vida pueda sostenerse más que en la mutua afectación de lo viviente, incluida la muerte como uno de los modos más radicales de afectación y que, sin embargo, no implica la aniquilación de la vida sino su constante posibilidad. Por supuesto, habrá diferencias entre esos múltiples modos de afectación de acuerdo con las posibilidades corporales y las diversas alianzas que se establezcan, pero pensar la resistencia desde esta mirada hará que necesariamente la arranquemos del monopolio de lo humano y de la política en mayúsculas, así como de la agencialidad del sujeto moderno.

La vulnerabilidad no significa ser víctima, aunque puede quedar aprisionada en esa condición mediante los distintos dispositivos paternalistas que en la actualidad se ponen en marcha para proteger $l a$ vida. Dispositivos que son ante todo inmunitarios, pues capturan su potencia y la colocan en una eterna pasividad reforzadora del orden de las cosas. Al contrario de la noción de víctima, la vulnerabilidad tiene que ver con lo expuesto, lo abierto, lo incierto, mientras que la víctima requiere seguridad y protección: "Somos vulnerables no solo entre nosotros - un rasgo invariable de las relaciones sociales- sino que esta misma vulnerabilidad indica una relación más amplia de dependencia e interdependencia que cambia la manera dominante de entender ontológicamente al sujeto corporizado" (Butler, 2018, p. 42).

Como se refirió al inicio de este escrito, las actuales condiciones biopolítico-inmunitarias se sostienen en mecanismos securitarios frente a todo aquello que suponga una amenaza a la forma de vida dominante, juega con la exposición y la inclusión, segmentando a la población entre expuestos e incluidos favoreciendo con esto el conflicto civil. Acompañamos a Butler (2018) cuando afirma que: 
la vulnerabilidad no es una disposición subjetiva, sino una relación con un campo de objetos, fuerzas y pasiones que inciden y nos afectan de alguna manera. Como un modo de estar relacionado con lo que no soy yo y que no es plenamente controlable, la vulnerabilidad es un tipo de relación que pertenece a esa ambigua región en que la receptividad y la capacidad de respuesta no son claramente separables una de otra y no se distinguen como momentos separados en una secuencia; de hecho, donde la receptividad y la capacidad de respuesta se convierten en la base para la movilización de la vulnerabilidad en vez de incitar su negación destructiva. (p. 49).

La vulnerabilidad, siguiendo a esta autora, no es pasiva ni activa por sí misma, pero sí es condición de posibilidad de la resistencia. Aunque es posible afirmar que existir es estar inmersos en ese campo de fuerzas objetivas que nos afectan y en las que incidimos, también es necesario no olvidarnos de los mecanismos de vulnerabilización que se ponen en marcha desde el régimen biopolítico-inmunitario constituyendo poblaciones más vulnerables que otras, es decir, más expuestas. $\mathrm{Y}$ es precisamente en quienes se encuentran más expuestos y por ello menos inmunizados donde es posible resistir; en cambio, donde la inmunidad es casi total no habrá posibilidades del reconocimiento de vulnerabilidad, pues esta será evitada a toda costa; lo que habrá ahí, como señala Brossat (2008), es anestesia, imposibilidad de afectación.

Respecto de esto, resulta interesante pensar algunos movimientos -varios de ellos efímeros- de la actualidad, donde lo que se exige es precisamente intensificar las medidas biopolítico-inmunitarias de los gobiernos actuales: más seguridad, más vigilancia, más policía, más protección. Contrariamente de esto, resistir es exponerse, incluso como refiere Butler- deliberadamente a diversos riesgos como persecución, represión, criminalización o encarcelamiento, porque se hace de ello un acto corporal y político:

Toda reunión pública está acechada por la policía y la cárcel. Y toda plaza pública se define en parte por la población que podría no llegar a ella; ya sea porque son detenidos en sus límites, o no tienen libertad de movimiento y reunión o están arrestados y encarcelados. En otras palabras, la libertad para reunirnos en tanto que personas siempre está acechada por la detención de aquellos 
que ejercieron esa libertad y fueron encarcelados. Y cuando llegamos a espacios públicos o comunes con puntos de vista radicales y críticos, siempre hay una cierta expectativa -imaginada o real- que se produzca una detención. A veces andamos o corremos a sabiendas en dirección a la cárcel, porque es el único modo de exponer las restricciones ilegítimas sobre la reunión pública y la expresión política.

Así, más allá de que desde la misma democracia exista el derecho a la protesta, la resistencia, la insurrección y los procesos emancipatorios siempre correrán en dirección contraria a esta. La lucha social estará siempre por fuera de la lógica de la ley y el derecho, aunque en su camino pueda parecer que encuentra refugio temporal en la misma y si lo hace, será siempre de manera estratégica. No es que la resistencia busque exponerse a toda costa a los riesgos, es que resistir implica estar inevitablemente en riesgo de ser afectado. Ahora bien, afectar y ser afectado, como lo indica no es un dejarse llevar, es un hacer frente a una afectación particular que requiere de cierta prudencia y, por lo tanto, necesita de una lectura cartográfica de las afectaciones en las que estamos implicados y de las derivas que deseemos tomar.

\section{Resistencia como poder destituyente}

La resistencia social, particularmente durante el siglo pasado había tomado ángulos enmarcados en un anhelo de poder constituyente como oposición al poder constituido: aspiración a constituir otro Estado como resultado de una revolución proletaria. Actualmente, a la luz de las revoluciones proletarias que ocurrieron a lo largo del siglo XX y su actual derrota e incorporación al orden capitalista, otro imaginario se configura como necesario. En América Latina, por ejemplo, el resurgimiento de gobiernos progresistas de izquierda no ha sido suficiente, pues se han tenido que enfrentar a una maquinaria global capitalista que les ha dejado poco espacio de acción y que ha provocado un efecto de rebote ahí donde emergieron, con el regreso de gobiernos abiertamente derechistas y neoliberales, como ha pasado en Brasil o Chile.

Ante estos efectos de los anhelos constituyentes emerge un imaginario de insurrección que no pretende instituirse de ninguna manera, 
sino desagregarse, desertar, fugarse. Colocarse en la constante insurrección. Esto es lo que Agamben (2014) llama la potencia destituyente:

si al poder constituyente corresponden revoluciones, motines y nuevas constituciones, es decir, una violencia que funda o constituye un nuevo derecho, para la potencia destituyente se deben pensar estrategias completamente diferentes, cuya definición es la tarea política de lo que viene. Un poder que solo ha sido derribado con una violencia constituyente resurgirá tomando otra forma, en la incesante, inconsignable, desolada dialéctica entre poder constituyente y poder constituido, violencia que funda el derecho y violencia que lo conserva. (párrafo 14).

Agamben sostiene que la potencia destituyente es capturada a través del poder constituyente y neutralizada por este, haciendo que el primero no dirija su fuerza contra el orden jurídico, sino solamente contra alguna figura histórica suya. En las actuales discusiones desde la filosofía política el debate respecto del poder constituyente y la potencia destituyente es de gran relevancia por sus apuestas prácticas y la comprensión de las resistencias y las insurrecciones. Existen quienes todavía consideran primordial la apuesta por lo constituyente y lo vinculan, por ejemplo, a la idea de multitud como el actual sujeto revolucionario y como ejemplo de la vida en común, elaboración que todavía está demasiado enmarcada en el pensamiento político clásico y que aspira a que una minoría pueda convertirse en mayoría; idea sostenida por autores como Antonio Negri (2007). Por otro lado, están quienes - como Agamben - apuestan por una política por venir, una que no puede estar enmarcada en las lógicas clásicas y dominantes que nos han enseñado a través de los siglos, que son insuficientes y no pueden ser pensadas de manera universal; una política más allá del Estado y su democracia. Para esto, será necesario salirnos del dispositivo de la eterna dialéctica fundante de la violencia, de la resistencia que vuelve a constituir poder. Agamben (2016), siguiendo a Benjamin, sostiene que una vía a través de la cual podemos desprendernos de ese dominio ontológico y por lo tanto político, es volver inoperoso ese poder, lo cual

significa volver inoperante, desactivar una obra. No se trata de la inercia, o de no hacer nada (que también es importante), sino de una forma de acción, de praxis o de obra, una operación que consistiría en resobrar las obras. (párrafo 36). 
Es decir, quitarle el fundamento de sentido que lo hace efectivo, actuante sobre nosotros:

Solo es neutralizado íntegramente un poder que ha sido vuelto inoperoso y que ha sido depuesto a través de una violencia que no mira a fundar un nuevo derecho. Benjamin identificaba esta violencia -o, según el doble significado del término alemán Gewalt, este "poder destituyente" - con la huelga general proletaria, que Sorel oponía a la huelga simplemente política. Mientras la suspensión del trabajo en la huelga política es violenta, "porque provoca [veranlasst, "ocasiona", "induce"] solo una modificación extrínseca de las condiciones de trabajo, la otra, como medio puro, está exenta de violencia". Ella, de hecho, no implica el retorno al trabajo "luego de concesiones exteriores y algunas modificaciones de las condiciones laborales", sino la decisión de reanudar el trabajo solo si este ha sido íntegramente transformado y no es impuesto por el Estado, es decir, implica una "alteración que este tipo de huelga no provoca [veranlasst], sino que más bien realiza [vollzieht]". En la diferencia entre veranlassen, "inducir, provocar", y vollziehn, "cumplir, realizar", se expresa la oposición entre el poder constituyente, que destruye y recrea siempre nuevas formas de derecho, sin jamás destituirlo definitivamente, y la violencia destituyente que, en la medida en que depone de una vez por todas el derecho, inaugura inmediatamente una nueva realidad. "De ahí que la primera de estas operaciones da existencia a un derecho, mientras que la segunda, en cambio, es anárquica. (Agamben, 2014, párrafo 22).

Lo destituyente configura formas-de-vida, no se queda atrapado en reivindicaciones fragmentadas ni representacionales, no aspira a reformas; su objetivo no es obtener un derecho o una garantía individual, no pretende la repartición de privilegios ni anhela la inclusión inmunitaria, no defiende identidades particulares ni tendrá como objetivo la exigencia o mejoras de la infraestructura. Su acción, como señala Agamben, se coloca en el afectar efectuándose, en el devenir constante, en el ahora que referimos líneas atrás. En la implicación inmediata con el mundo que no está atravesada por la racionalidad moderna ni por una finalidad última. Lo destituyente requiere, según Agamben (2016):

hacer uso del cuerpo, y eso querría decir la afectación que experimentamos al estar en relación con otros cuerpos. Desde mi punto 
de vista, eso es la vida, como lugar verdadero de lo político. Si hay un sujeto político, es aquel que se ve afectado por su relación con otros cuerpos. (párrafo 30).

Y esto solo puede ocurrir cuando lo común se pone en marcha. Para el Colectivo Situaciones (2002), la destitución:

parece ser una operación de significación mayor: si la política realizada en términos de institución soberana encuentra su punto de ser en la constitución estatal de lo social, la acción destituyente parece postular otra vía de practicar la política, de enunciar el cambio social. Tal destitución no implica una apolítica: la renuncia a sostener una política representativa (de soberanía) es condición -y premisa- de un pensar situacional y de un conjunto de prácticas cuyos sentidos ya no son demandas al Estado. (p. 43).

Cuando se realiza ese desplazamiento que parece sutil, pero es sumamente poderoso, se abren las posibilidades de otra política que no pretende ser constituyente porque no pretende fundar otro Estado con su sociedad, o mejorar la democracia, ni siquiera desea otra democracia. Irrumpe en los límites de la imaginación política y de la vida que conocemos. Ahora bien, esta fractura o apertura que se puede poner en marcha respecto de lo constituyente y constituido no es algo que pueda ocurrir fácilmente, pues los múltiples dispositivos de ordenamiento están por todos lados, particularmente porque han penetrado de manera profunda en nuestra subjetividad (no solo operan fuera, sino dentro de nosotros). Y porque además de esto el mismo orden en el que vivimos procede de manera anárquica (Agamben, 2016).

$\mathrm{Si}$, como hemos argumentado al inicio del artículo, el tipo de poder que experimentamos se vierte sobre la vida misma separándola entre la vida política (bíos) y la vida biológica (zoé), reduciéndola a nuda vida, esto es, vida administrable que es capturada en una serie de mecanismos inmunitarios que terminan arrancándole su potencia vital; es precisamente desde la vida que la resistencia tiene que emerger, no como oposición y contención eterna que deriva en el mantenimiento del orden, sino como la puesta en marcha de otros modos de afectación que traspasen la noción de resistencia y configuren efectivamente otra forma-de-vida, como una fuga a ese dominio. La vida en ese sentido será insurrección en acto y no meta ni utopía, insurrección porque 
destituye los fundamentos operantes, en sus dimensiones macro y micropolíticas y en sus alcances objetivos y subjetivos.

\section{Habitar y resistir, aportes desde Latinoamérica}

"Poner lo humano en el centro era el proyecto occidental". Ya sabemos a dónde ha llevado. Ha llegado el momento de abandonar el barco, de traicionar la especie. No existe ninguna gran familia humana que exista de manera separada a cada uno de los mundos, de cada uno de los universos familiares, de cada una de las formas de vida que siembran la tierra. No existe ninguna humanidad, solo existen terrestres. Nosotros, los revolucionarios, con nuestro humanismo atávico, haríamos bien en fijarnos en los levantamientos ininterrumpidos de los pueblos indígenas de América Central y América del Sur durante los últimos veinte años. Su consigna podría ser "Poner la tierra en el centro. Se trata de una declaración de guerra al Hombre. Declararle la guerra: esa podría ser una buena manera de hacerle volver sobre la tierra, sino se hiciera el sordo, como siempre.

Comité INVISIBLE

Parte de lo que hemos sostenido hasta aquí es cómo las condiciones materiales en que hoy se da la existencia son prácticamente invivibles, pues solo las podemos vivir en su dimensión administrada, biopolítica e inmunitaria. No solo es que el mundo sea actualmente inhabitable: ¿cómo es que podemos vivir en condiciones absolutamente contaminadas y devastadas? Sino que hemos renunciado desde hace siglos al ejercicio de habitar el mundo, particularmente quienes hemos sido occidentalizados. Vivir implica habitar, vincularnos con nuestro entorno, configurar un hábitat. Sin embargo, nuestros días transcurren al interior de una infraestructura que no diseñamos y muchas veces no pedimos.

Sin embargo, para la mayoría de los pueblos ancestrales alrededor del planeta el llamado a configurar una forma-de-vida como vía para desagregarse de la vida capturada por la gestión biopolítica inmunitaria del neoliberalismo ha sido desde siempre una manera cotidiana de existir. Su forma-de-vida, como señala Raquel Gutiérrez (2008) está directamente vinculada con el ritmo vital de la tierra, lo que los aimaras denominan Patchakuti. Cada rasgo de su forma de vida tiene que entrar en cadencia con ese ritmo, la falta de armonía implica poner en riesgo todas las formas de vida, incluida la suya. 
El orden capitalista-neoliberal en su forma biopolítica-inmunitaria ahoga ese ritmo, lo satura. Pero a su vez, la existencia de esas formasde-vida que no se adscriben a la administración vuelven inoperoso ese poder, tal y como lo referimos anteriormente, pues su vida no genera plusvalía, genera riqueza para la comunidad. Dávalos (2010) señala que mientras el resto de los movimientos sociales durante el siglo $\mathrm{XX}$ se dedicaron a pedir derechos al Estado, los pueblos ancestrales se dedicaron a defender su forma-de-vida y a organizar otras maneras de hacer lo político. Así, las actuales luchas por la defensa del territorio constituyen a su vez una defensa de la forma-de-vida, defender la tierra es defender las múltiples formas de vida. Para los pueblos ancestrales no hay otra forma de habitar que no sea en común, para los occidentalizados y colonizados el volver a lo común es un llamado, para ellos, es en sí mismo la vida que no está escindida entre bíos y zoé.

Así, la forma-de-vida no neoliberal solo puede emerger en relación con un habitar determinado anclado en un territorio. Habitar un territorio se contrapone al habitar la infraestructura diseñada por el orden actual, no se trata de destruirla, sino de destituirla, habitarla por fuera del mandato administrativo. Habitar en común tiene que ver con el buen vivir como afirmación política que tanto han defendido los pueblos indígenas; esta noción, según la antropóloga maya Aura Cumes (2014):

no es solamente un pensamiento, una filosofía o una teoría, es antes que nada una experiencia de vida. Es decir, es a la vez un pensar, un vivir y un sentir. En tanto es una manera de experimentar la existencia es profundamente espiritual. En esta concepción de la vida se enseña que todo vive: la tierra, las montañas, el agua, las plantas, el sol, la luna, las estrellas, así como todo lo que no vemos pero tiene movimiento. Así, el universo se compara con un gran tejido; animales, seres humanos y todo cuanto vive, somos un hilo de ese tejido. Todo está interconectado, interrelacionado, es complementario e interdependiente, de modo que el deterioro de algo desencadena la descomposición de todo. (p. 8).

Las múltiples resistencias que recorren Latinoamérica en los años recientes reconocen cada vez más este saber que se mantiene y se actualiza desde los pueblos ancestrales, se comparte, se nutre y se transforma. Este resistir desde la existencia misma funda otra política, que 
no se sostiene en la relación dialéctica con el poder estatal, ni tiene como finalidad última la fundación de más derechos - aunque no se opone a ello-, sino que corre subterráneamente por otra vía, una vía ontológica y epistemológicamente distinta de la política occidental, incluso respecto de su misma forma democrática occidental, porque al colocar lo común como apuesta emancipatoria la idea democrática - con su individuo autónomo y racional - queda destituida (Nava, 2019). Por supuesto que estos rasgos no aparecen de modo exclusivo en nuestra región, sin embargo, el modo en que se expresa en diversas resistencias - sean ancestrales o no- tiene que ver con el vínculo que aún con los siglos de colonización, apropiación y exterminio se sigue manteniendo respecto de otros modos de organizarse, de hacer política y de existir. En este sentido, la apuesta desde el cuerpo, el territorio y la vulnerabilidad constituyen rasgos fundamentales de los modos de resistir desde y en Latinoamérica. $\mathrm{Al}$ respecto, la pensadora mapuche María Moreno (2020) señala:

La recuperación del trabajo con el cuerpo como vehículo creativo, emancipatorio y creador de conocimientos, espacio de memorias. Creemos que el cuerpo ha sido despojado de su sensibilidad, de su carne, de sus vísceras, de sus miserias, de sus gozos y sus placeres, por lo tanto, nosotras lo ponemos como centro en nuestros diálogos y metodologías. Deseamos que el cuerpo hable "de sí" y es en esta apertura donde encontramos la emergencia de la rebeldía para la construcción de otros mundos posibles. (párrafo 19).

La vida en común solo puede darse en lo que está abierto a lo múltiple, en lo que dispone una forma de vida común en el habitar y no en el ser, como nos lo mostró el nacismo a principios del siglo XX y lo está mostrando la derecha ultraconservadora de diversos gobiernos actuales en Latinoamérica y el resto del mundo con sus políticas segmentarias e inmunitarias. Ante ello, es indispensable repensar el modo en que construimos alianzas y comunidad, si es que pretendemos resistir no como aguante o permanencia, sino como creación de vida, insistencia y territorialidad.

\section{Referencias}

Agamben, G. (2014). Para una teoría del poder destituyente. Fractal. Revista de teoría y cultura, (74). https://www.mx- 
fractal.org/articulos/RevistaFractal74GiorgioAgamben. php?fbclid=IwAR1FQgSygtHHCG_IopoVRawAT6uaoSoRDNIVTyDBXNHVaxMvmuryGBcQ9H4

Agamben, G. (15 de junio de 2016). Hacia una teoría de la potencia destituyente. Artillería Inmanente. https://artilleriainmanente. noblogs.org/?p=308

Banerjee, I. (2014). Mundos convergentes: Género, subalternidad, poscolonialismo. La ventana. Revista de Estudios de Género, 5(39), 7-38. http://www.scielo.org.mx/scielo. php?script=sci_arttext\&pid=S1405-94362014000100003

Benjamin, W. (2001). Para una crítica de la violencia y otros ensayos. Iluminaciones $I V$. Taurus.

Berardi, F. (2013). Félix. Narración del encuentro con el pensamiento de Guattari. Cartografía visionaria del tiempo que viene. Cactus.

Bordeleau, E. (2019). Foucault anonimato. Cactus.

Brossat, A. (2008). La democracia inmunitaria. Palinodia.

Butler, J. (24 de junio de 2014). Repensar la vulnerabilidad y la resistencia. XV Simposio de la Asociación Internacional de Filósofas (IAPh), Alcalá de Henares, España.

Butler, J. (2018). Resistencias. Paradiso.

Colectivo Situaciones (2002). 19 y 20. Apuntes para el nuevo protagonismo social. Ediciones de mano en mano.

Comité Invisible (2015). A nuestros amigos. Pepitas de calabaza.

Comité Invisible (2017). Ahora. Pepitas de calabaza.

Cumes, A. (2014). Prólogo. El Ütz'ilaj Kaslemal - El Raxnaquil Kaslemal. El Buen Vivir: de los Pueblos de Guatemala. Confluencia Nuevo B'aqtun.

Dávalos, P. (2010). La democracia disciplinaria. El proyecto posneoliberal para América Latina. Cooperación para el Desarrollo de la Educación Universitaria, CO-DEU.

Espósito, R. (2009). Comunidad, inmunidad y biopolítica. Herder.

Estévez, A. (2018). Biopolítica y necropolítica: ¿constitutivos u opuestos? Espiral (Guadalajara), 25(73). http:// www.scielo.org.mx/scielo.php?script=sci_arttext\&pid $=$ S1665-05652018000300009

Foucault, M. (2000). Defender la sociedad. Fondo de Cultura Económica. 
Garcés. M. (2002). Posibilidad y subversión. Espai en Blanc. Materiales para la subversión de la vida. http://espaienblanc. net $/$ ?page_id $=477$

García Canal, M. (2005). Espacio y poder en Michel Foucault. Universidad Autónoma Metropolitana, UAM-Xochimilco.

Gutiérrez, R. (2008). Los ritmos del Pachakuti. Movilización y levantamiento popular-indigena en Bolivia (2000-2005). Tinta Limón.

Gutiérrez, R. (10 de octubre de 2017). En Chile el movimiento indígena no se ha encandilado con las políticas multiculturales ligadas a la idea neoliberal. Noticias Universidad de Chile. https://www.uchile.cl/noticias/137689/raquel-gutierrez-elmovimiento-indigena-no-se-ha-encandilado

Han, B-C. (2016). Topología de la violencia. Herder.

Latour, B. (29 de marzo de 2019). El sentimiento de perder el mundo, ahora, es colectivo. El País. https://elpais.com/elpais/2019/03/29/ideas/1553888812_652680.html

Lonzi, C. (2004). Escupamos sobre Hegel y otros escritos. Traficantes de sueños.

Lopetegi de la Granja, E. (2009). Para una crítica del conflicto vasco. Espai en Blanc. Materiales para la subversión de la vida. Bellaterra.

Modonesi, M. (2006). Resistencia: subalternidad y antagonismo. Revista Rebelión. https://rebelion.org/resistencia-subalternidady-antagonismo/

Moreno, M. (2020). Del cuerpo-territorio como re-apropiación para re-existencias emancipatorias. Reflexiones Marginales, (57). https://revista.reflexionesmarginales.com/del-cuerpo-territorio-como-re-apropiacion-para-re-existencias-emancipatorias/

Nava, M. (2019). De la democracia biopolítico-inmunitaria a las posibilidades de habitar en común desde Latinoamérica. Reflexiones Marginales, (52). https://revista.reflexionesmarginales.com/de-la-democracia-biopolitico-inmunitaria-a-las-posibilidades-de-habitar-en-comun-desde-latinoamerica/\#: :text=La\%20condici\%C3\%B3n\%20 inmunitaria\%20de\%20la,se\%20considere\%20de\%20peligro\%20o 
Negri, A. (2007). El poder constituyente. http://biblioteca.clacso.edu. ar/clacso/coediciones/20140805042026/06poder.pdf

Preciado, P. (2019). Prólogo. Esferas de la insurrección. Traficantes de sueños.

Rolnik, S. (2019). Esferas de la insurrección. Traficantes de sueños. 